\title{
Role of E-selectin and platelet endothelial cell adhesion molecule 1 in gastritis in food allergy patients
}

\author{
Małgorzata Graczyk ${ }^{1}$, Michał Przybyszewski ${ }^{1}$, Andrzej Kuźmiński' ${ }^{1}$ Jacek Tlappa², Jacek Mućka², \\ Katarzyna Napiórkowska ${ }^{1}$, Ewa Szynkiewicz ${ }^{1}$, Magdalena Żbikowska-Gotz ${ }^{1}$, Zbigniew Bartuzi ${ }^{1}$
}

1Department of Allergology, Clinical Immunology and Internal Diseases, Ludwik Rydygier Collegium Medicum, Nicolaus Copernicus University, Dr. J. Biziel Memorial University Hospital No. 2, Bydgoszcz, Poland

Head of Department: Prof. Zbigniew Bartuzi MD, PhD

2Emergency Medicine Department, Dr. J. Biziel Memorial University Hospital No. 2, Bydgoszcz, Poland

Head of Department: Jacek Tlappa MD, PhD

Postep Derm Alergol 2013; XXX, 5: 271-276

DOI: 10.5114/pdia.2013.38354

\begin{abstract}
Introduction: The prevalence of food allergies and other allergic reactions is increasing worldwide, particularly in highly-urbanized populations. Cell adhesion molecules are expressed in response to various pro-inflammatory cytokines. The expression of intercellular adhesion molecule 1-ICAM-1 (CD54), ICAM-1 (CD106), P-selectin (CD62P), and E-selectin (CD62E) on vascular endothelial cells is induced by such pro-inflammatory cytokines as tumor necrosis factor $\alpha$ (TNF- $\alpha$ ) and interleukin-1 (IL-1).

Aim: To analyze concentrations of E-selectin and platelet endothelial cell adhesion molecule-1 (PECAM-1) in patients with an allergic type of food sensitivity co-existing with gastritis and to compare them to the values determined in individuals with dyspeptic symptoms not associated with allergic disorders.

Material and methods: The study included 80 patients, among them 50 individuals with food sensitivity confirmed based on compulsory standards, and 30 subjects with dyspeptic symptoms not accompanied by allergic conditions. Venous blood samples were taken from each patient and concentrations of E-selectin and PECAM-1 were determined by means of ELISA.

Results: Mean concentrations of sE-selectin and sPECAM-1 in patients with food allergy amounted to $54.0 \pm 21.6 \mathrm{ng} / \mathrm{ml}$ and $132.8 \pm 31.4 \mathrm{ng} / \mathrm{ml}$, respectively. In individuals without food allergy, mean concentrations of sE-selectin and sPECAM-1 were $57.7 \pm 17.9 \mathrm{ng} / \mathrm{ml}$ and $139.6 \pm 31.1 \mathrm{ng} / \mathrm{ml}$, respectively. Patients with food allergy and individuals with dyspeptic symptoms not associated with food allergy did not differ significantly in terms of sE-selectin concentrations (Mann-Whitney $U$-test, $p=0.453028$ ). Similarly, no significant intergroup differences were observed with regard to SPECAM-1 concentrations (Mann-Whitney U-test, $p=0.231054$ ).

Conclusions: Adhesion molecules play an important role in the development of inflammation. This study did not find significant differences in the concentrations of such molecules as sE-selectin and SPECAM- 1 between patients with food allergy and gastritis, and subjects in whom gastritis was not accompanied by atopic disorders. A positive correlation between the concentrations of SPECAM-1 and E-selectin was observed in food allergy patients. Consequently, it can be concluded that these molecules participate in the pathogenesis of the inflammatory process independently of the etiopathogenesis of gastritis.
\end{abstract}

Key words: food allergy, gastritis, sPECAM-1, sE-selectin.

\section{Introduction}

The prevalence of food allergies and other allergic reactions is increasing worldwide, particularly in highly-urbanized populations [1-3]. The problem of food allergy is better recognized in developmental age populations rather than in adults, mostly due to the difficulties in establishing causative relationships between ingested (harmful) food and disease symptoms occurring within a specific time following its ingestion [4]. Cell adhesion molecules are known to play a vital role in the pathogenesis of allergic diseases and inflammatory processes. These molecules are

Address for correspondence: Małgorzata Graczyk MD, PhD, Department of Allergology, Clinical Immunology and Internal Diseases, Ludwik Rydygier Collegium Medicum, Nicolaus Copernicus University, Dr. J. Biziel Memorial University Hospital No. 2, 75 Ujejskiego St, 85-345 Bydgoszcz, Poland, phone: +48 5236554 16, fax: +48 5234840 76, e-mail: gosgra1@poczta.onet.pl Received: 18.09.2012, accepted: 8.09.2013. 
expressed in response to various pro-inflammatory cytokines. The expression of intercellular adhesion molecule 1- ICAM-1 (CD54), ICAM-1 (CD106), P-selectin (CD62P), and E-selectin (CD62E) on vascular endothelial cells is induced by such pro-inflammatory cytokines as tumor necrosis factor- $\alpha$ (TNF- $\alpha$ ) and interleukin-1 (IL-1) $[5,6]$. The family of selectins includes three transport glycoproteins: leukocyte $(L)$, platelet $(P)$, and endothelial (E) selectins [7]. These molecules share a common structural pattern [7]. The expression of E-selectin is not modulated by IL-6 and IL-8 [8]. Specialized receptors for adhesion molecules are expressed on endothelial cells under the influence of pro-inflammatory cytokines. These receptors show high kinetics towards formation of the basis for binding of circulating leukocytes [6]. Depending on their structural characteristics, adhesion molecules involved in leukocyte aggregation can be classified into three groups: selectins, integrins, and the immunoglobulin superfamily. Selectins are expressed in blood vessels. E-selectin present on endothelial cells possesses a 95-115 kDa molecular mass and the locus of its gene has been pinpointed to 1q21-24. E-selectin is predominantly involved in the initiation of the adhesion process and supports leukocyte rolling and adhesion to the vascular wall [8, 9]. Platelet endothelial cell adhesion molecule-1 (PECAM-1) (CD31) is involved in adhesion and is expressed on the lateral surfaces of endothelial cells and on blood platelets [10]. Similar to ICAM2 , the expression of PECAM-1 is not significantly changed by inflammatory mediators [11]. This molecule is present on $95 \%$ of monocytes and neutrophils as well as on approximately $50 \%$ of peripheral blood lymphocytes. The PECAM1 is constitutively expressed by all vascular cells and represents a useful immunohistochemical marker of peripheral vessels, particularly during angiogenesis [12].

\section{Aim}

The aim of this study was to analyze concentrations of E-selectin and PECAM-1 in patients with an allergic type of food sensitivity co-existing with gastritis and to compare them to the values determined in individuals with dyspeptic symptoms not associated with allergic disorders.

\section{Material and methods}

This study included a total number of 80 patients. The group of patients with food allergy and gastric symptoms was comprised of 50 subjects, 33 women and 17 men aged between 18 and 65 years (mean of 38.36 years). The group of patients with dyspeptic symptoms without the allergy was comprised of 30 subjects, 23 women and 7 men aged between 18 and 54 years (mean of 29.96 years). All participants of the study were treated at the Clinic of Allergology, Clinical Immunology and Internal Diseases of the Ludwik Rydygier Collegium Medicum at the Nicolaus Copernicus University (CM NCU) in Bydgoszcz and at the
Food Allergy Outpatient Clinic. Food allergy was confirmed based on the results of a detailed history and physical examination suggesting a causative relationship between observed symptoms and ingested foods and included positive results of skin tests with alimentary allergens, use of the elimination diet, and determination of IgE antibodies. Study inclusion criteria included the presence of epigastric pain and other gastric symptoms such as heartburn, regurgitation, bloating, and vomiting. All participants reported abdominal pain. Additionally, patients with coexisting food allergy reported burning of lips and tongue, heartburn, nausea, vomiting, and diarrhea following the consumption of sensitizing foods. Moreover, numerous subjects experienced urticaria-like skin lesions, Quincke's edema, and generalized itching of the skin. Respiratory symptoms were also observed; most commonly, rhinorrhea and dyspnea. The exclusion criteria included treatment with antihistaminic or anticoagulant agents, cardiac and pulmonary diseases, ulcerative colitis, Crohn's disease, post gastrectomy or intestine resection status, fungal infections of the alimentary tract, tuberculosis, malignancies, and connective tissue disorders. Patients in whom dyspeptic symptoms were not accompanied by food allergy had no personal or familial history of atopic disorders, as well as had negative results of skin tests with alimentary allergens. Additionally, venous blood samples were taken from each patient to determine the concentration of sE-selectin and sPECAM-1 by means of ELISA (Bender MedSystems).

\section{Allergological evaluation}

Skin tests with alimentary allergens were carried out in all participants. The tests were carried out with standard procedures using the PRICK method and standard alimentary allergen kits (Allergopharma). The result of the test was considered positive if the reaction to the tested allergen (blister diameter) was equal to or greater than the reaction to histamine. Additionally, serum concentration of total IgE was determined in each patient by means of fluoroenzymoimmunoassay (FEIA) on UniCAP 100 device (Phadia). All tests were conducted at the Immunological Laboratory of the Clinic of Allergology, Clinical Immunology and Internal Diseases at CM NCU and Dr. J. Biziel Memorial University Hospital No. 2 in Bydgoszcz.

\section{Histopathological examination}

All patients underwent the endoscopic examination of the upper alimentary tract with GIF-E fiberscope (Olympus). Macroscopic appearance of the gastric mucosa, its motility, and the secretory activity were examined. Additionally, mucosal biopsies were taken from the antrum $(n=2)$ and the corpus $(n=2)$ for histopathological verification and testing for Helicobacter pylori infection. The biopsies were obtained from normal and inflamed gastric mucosa (not from erosions or ulcerations). Histopathological examination was performed at the Department of Path- 
omorphology at Dr. J. Biziel Memorial University Hospital No. 2 in Bydgoszcz. Histopathological slides were stained with hematoxilin, eosin, and Giemsa's stain. The presence, activity and degree of gastric mucosa inflammation were graded using the routine Sydney system with the Houston modification. During the histopathological examination, special attention was paid to the composition of cellular infiltrate and the count of eosinophils in inflamed gastric mucosa. The evaluation was conducted by 10HPFx250 method. The presence of polynuclear cells within inflammatory infiltrate was considered as a sign of active inflammation (gastritis chronica activa). The presence of colonization with Helicobacter pylori was analyzed histopathologically using hematoxilin, eosin, and Giemsa's staining and expressed as (+), while the lack of the bacterium was designated as $(-)$.

\section{Statistical analysis}

Continuous variables were presented as arithmetic $(x)$ and geometric means $(g)$ as well as standard deviations (s). The significance of intergroup differences in studied parameters was analyzed with the Mann-Whitney U-test.

\section{Results}

\section{Histopathological examination of gastric mucosal biopsies}

Gastroscopy was performed in 80 patients. The histopathological examination of antral biopsy specimens revealed chronic gastritis in 41 (82\%) patients from the food allergy group, including 16 (32\%) cases with the signs of active inflammation of the antral region. Corporal specimens showed inflammation in 33 (66\%) subjects from the food allergy group, including 10 (20\%) cases with the signs of reactive gastritis. Co-existence of antral and corporeal gastritis was observed in 33 (66\%) patients. In 4 (8\%) cases from the food allergy group gastric mucosa was evaluated as normal (status normalis). The signs of antral gastritis were revealed in 23 (76.67\%) patients with dyspeptic symptoms not associated with food allergy; this group included $5(16.67 \%)$ cases of reactive gastritis. Corporal specimens showed inflammatory lesions in 15 (50\%) allergy-free patients; including one (3.33\%) case of reactive gastritis. Signs of simultaneous antral and corporeal inflammation were documented in 15 (50\%) individuals. Colonization with Helicobacter pylori was confirmed in 19 (38\%) subjects with food allergy and in 18 (60\%) allergy-free subjects. It was found in $40 \%$ of patients with food allergy $>10$ cells, eosinophils in the field of view at a magnification of 250x, whereas in patients without allergies eosinophils $>10$ in the field were observed in $10 \%$ of patients.

\section{Concentration of total serum IgE}

Mean values of total serum IgE in the group of patients with food allergy were $144.9 \mathrm{kU} / \mathrm{l}$, whereas in patients without allergy, the average concentration of total IgE was $80.124 \mathrm{kU} / \mathrm{l}$.

\section{The results of skin tests}

The results of skin tests with food allergens in the group of patients with food allergy were positive for: cocoa in $16 \%$ of patients, an apple in $50 \%$ of the respondents, peanut in $72 \%$, hazelnut in $68 \%$, chicken in $8 \%$, pork in $10 \%$, wheat in $46 \%$, rye flour in $30 \%$, egg hen in $12 \%$, milk in $10 \%$, fish in $38 \%$, banana in $12 \%$ and citrus in $64 \%$. In the group of patients with food allergy the main allergens are: nuts, citrus, apple, wheat flour and fish. Patients with documented food allergies were included in the study. Analyzing the clinical picture of patients with food allergy, and the results of additional tests, it seems that the test group of $50 \mathrm{pa}$ tients showed an immediate response to IgE-mediated food allergen ingested.

\section{Concentration of sE-selectin}

Mean concentration of sE-selectin in food allergy patients and in food allergy-free individuals amounted to 54.0 $\pm 21.6 \mathrm{ng} / \mathrm{ml}$ and $57.7 \pm 17.9 \mathrm{ng} / \mathrm{ml}$, respectively. The results of analyses are presented in Tables 1 and 2 .

Patients with food allergy and individuals with dyspeptic symptoms not associated with food allergy did not differ significantly with regard to sE-selectin concentrations (Mann-Whitney U-test, $p=0.453028$ ) (Figure 1).

\section{Concentration of SPECAM-1}

Mean concentration of SPECAM-1 amounted to 132.8 $\pm 31.4 \mathrm{ng} / \mathrm{ml}$ in patients with food allergy and to 139.6 $\pm 31.1 \mathrm{ng} / \mathrm{ml}$ in allergy-free individuals; this difference did not prove significant (Mann-Whitney U-test, $p=0.231054$ ). The results of analyses are presented in Tables 3 and 4, and Figure 2.

The correlation between concentrations of SPECAM-1 and sE-selectin is shown below in Table 5.

Table 1. Concentration of sE-selectin in patients with food allergy

\begin{tabular}{lc}
\hline Parameter & sE-selectin $[\mathrm{ng} / \mathrm{ml}]$ \\
\hline Sample size & 50 \\
\hline Arithmetic mean & 54.018 \\
\hline Standard deviation & 21.6352 \\
\hline Geometric mean & 48.794 \\
\hline Median & 55.50 \\
\hline Minimum & 7.20 \\
\hline Lower quartile & 36.70 \\
\hline Upper quartile & 70.80 \\
\hline Maximum & 100.00 \\
\hline
\end{tabular}


Table 2. Concentration of sE-selectin in patients without food allergy

\begin{tabular}{lc}
\hline Parameter & sE-selectin $[\mathrm{ng} / \mathrm{ml}]$ \\
\hline Sample size & 30 \\
\hline Arithmetic mean & 57.73 \\
\hline Standard deviation & 17.9231 \\
\hline Geometric mean & 55.0674 \\
\hline Median & 58.70 \\
\hline Minimum & 32.30 \\
\hline Lower quartile & 45.80 \\
\hline Upper quartile & 68.50 \\
\hline Maximum & 100.50
\end{tabular}

Table 3. Concentration of SPECAM-1 in patients with food allergy

\begin{tabular}{lc}
\hline Parameter & SPECAM-1 $[\mathrm{ng} / \mathrm{ml}]$ \\
\hline Sample size & 50 \\
\hline Arithmetic mean & 132.814 \\
\hline Standard deviation & 31.4448 \\
\hline Geometric mean & 129.430 \\
\hline Median & 126.850 \\
\hline Minimum & 84.80 \\
\hline Lower quartile & 112.00 \\
\hline Upper quartile & 144.80 \\
\hline Maximum & 212.60
\end{tabular}

Table 4. Concentration SPECAM-1 in patients without food allergy

\begin{tabular}{lc}
\hline Parameter & sPECAM-1 $[\mathrm{ng} / \mathrm{ml}]$ \\
\hline Sample size & 30 \\
\hline Arithmetic mean & 139.60 \\
\hline Standard deviation & 31.1351 \\
\hline Geometric mean & 136.3231 \\
\hline Median & 137.20 \\
\hline Minimum & 76.80 \\
\hline Lower quartile & 113.60 \\
\hline Upper quartile & 155.20 \\
\hline Maximum & 213.60 \\
\hline
\end{tabular}

\section{Discussion}

The gastrointestinal barrier plays a vital role in the prevention of food allergy. Injury of this barrier is reflected by

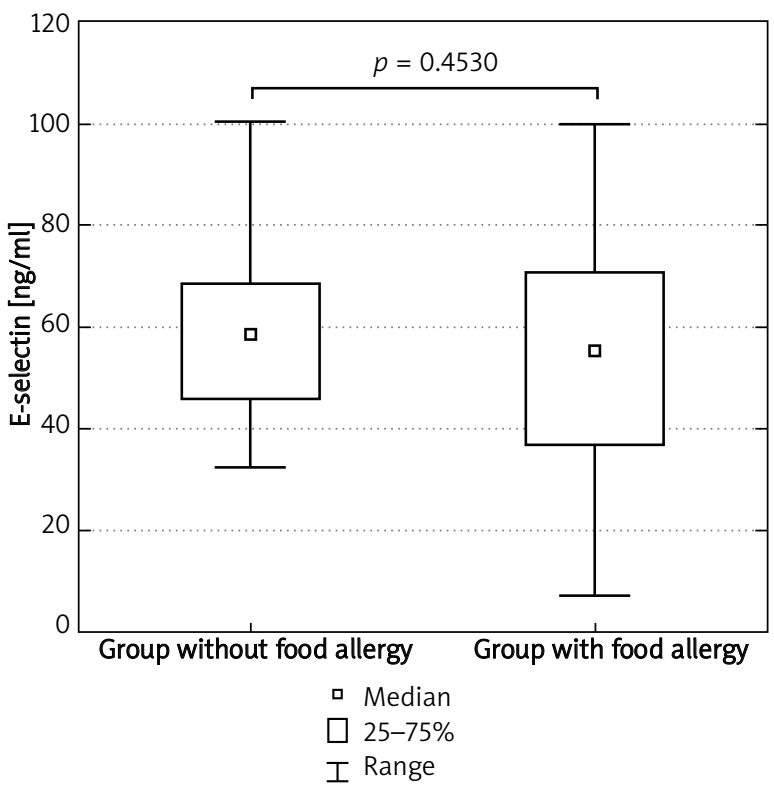

Figure 1. Concentration of sE-selectin in examined patients

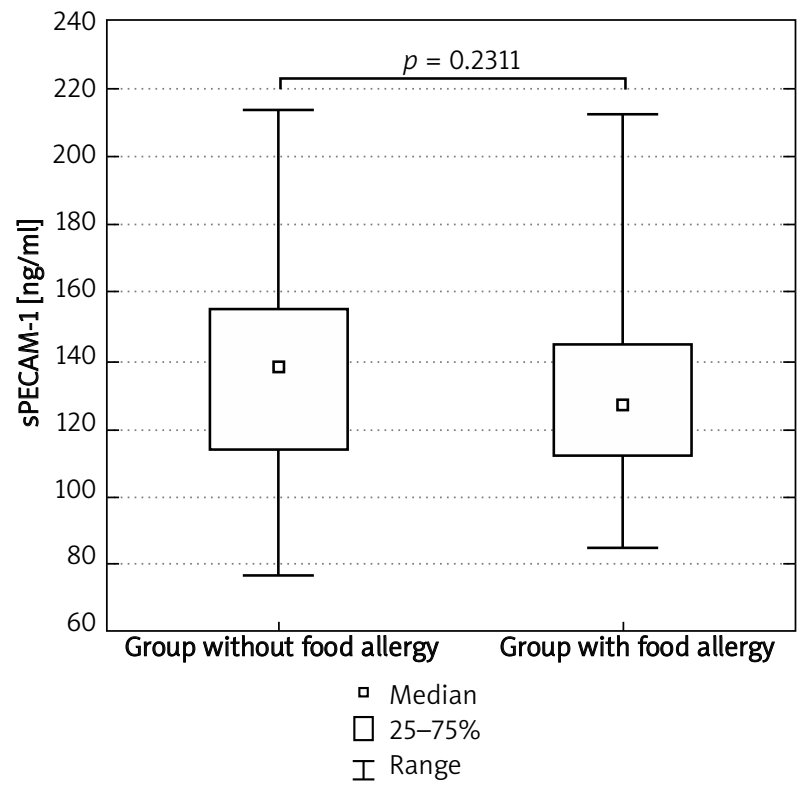

Figure 2. Concentration of sPECAM-1 in examined patients

an increased contact of allergens (antigens) with the mucosal immune system as well as by the release of many inflammatory mediators [13]. Due to its nearly undetectable expression on inactive cells, E-selectin is a highly sensitive marker of the inflammatory process [8]. Tsouknos et al. observed that monocytes induced the expression of E-selectin and vascular cell adhesion protein 1 (VCAM-1) on cultured endothelial cells, while the expression of P-selectin remained at a detection threshold. According to these 
authors, stimulation of endothelial cells with monocytes can enhance adhesion of circulating leukocytes. They hypothesized that this manner of endothelial cell activation and leukocyte recruitment can induce persistent inflammation, which can be involved in the development of vascular atherosclerotic lesions as well as inflammatory changes associated with other conditions [6]. Histamine is one of chemical mediators that play an established role in the pathology of allergic disorders. It is known to induce a transient expression of P-selectin and IL-6, but does not modulate the expression of ICAM-1, VCAM-1, and E-selectin [4]. It was confirmed that under physiological conditions, selected $B$ lymphocytes (plasma cells and memory $B$ cells), as well as activated $T$ lymphocytes, leave the lymph node and reach circulation via the efferent lymphatic vessels. Such lymphocytes, differentiated towards IgA secretion, infiltrate the mucosal membranes and remain there as the lamina propria lymphocytes [11]. The most important molecules regulating the migration of those cells into the mucosa are: 1) endothelial molecule MadCAM-1, whose ligands include integrin $\alpha 4 \beta 7$ located on the surface of lymphocytes colonizing mucosal membranes, and 2) chemokine CCL25 (TECK), which is synthesized in large amounts in the small intestine and binds to CCR9 receptor of lymphocytes $[11,14]$. Among others, interaction between L-selectin and integrin $\alpha 4 \beta 7$ present on naïve lymphocytes and MadCAM 1 molecules expressed on high endothelial venules (HEVs) determines the preferential lymphocyte colonization of Peyer's patches [11]. Depending on involved mechanisms, food sensitivity can be classified as IgE-dependent or lgE-independent food allergy. The immediate symptoms of IgE-dependent allergy result from the degranulation of mast cells modulated by specific IgE antibodies. Most commonly, acute urticaria, exacerbation of atopic dermatitis, upper or lower airway symptoms, and anaphylactic shock are observed in such cases [14, 15]. In contrast, gastrointestinal symptoms usually predominate in the IgE-independent processes. These reactions involve T lymphocytes and/or cytokines as well as other effector cells of the immune system. Involvement of these cells and their migration is confirmed by the fact that food allergy can manifest with many symptoms originating from various organs and systems, e.g. with conjunctivitis, asthma, or skin problems [14]. A number of studies point to the role of E-selectin as an inflammatory marker of atopic dermatitis and it has been found that the level of E-selectin correlates with the severity of the disease. However, a significant correlation between the level of E-selectin and the development of atopic conditions was not observed in the population of 2-year-old children [16]. Interesting findings were reported by Greenberger. This researcher studied the specimens of nasal and bronchial mucosa of allergic rhinitis patients $24 \mathrm{~h}$ after provocation with inhalatory allergen and observed significantly higher expressions of IL-5, eotaxin, ICAM-1, and E-selectin both in nasal and bronchial material. This suggests that allergenic stimulation of bone mar-
Table 5. Correlation between concentrations of sPECAM-1 and E-selectin in food allergy patients

\begin{tabular}{lccc}
\hline \multicolumn{2}{c}{ Correlation } & \multicolumn{2}{c}{ Patients with food allergy } \\
\hline Parameter & Parameter & $r$ & $p$ \\
\hline sPECAM-1 & sE-selectin & 0.323784 & 0.021804 \\
\hline
\end{tabular}

$r$-Spearman's coefficient of correlation; $p<0.05$

row cells is reflected by an elevated eosinophil and basophil count in peripheral tissues [17]. Cao et al. confirmed the involvement of endothelial PECAM-1 in angiogenesis in the murine model. According to these authors, PECAM1 can stimulate the mobility of endothelial cells in vivo, promoting the formation of phyllopodia $[18,19]$. Interaction with PECAM-1 molecules activates lymphocytes, inducing synthesis of many enzymes (such as zinc metalloproteinases, serine proteinases, plasmin, lysosomal cathepsins) and adhesion molecules, thus enabling the migration of these cells within the intercellular space [11]. Dudeck et al. analyzed the role of adhesion molecules modulating mast cells. The count of mast cells is known to increase at a site of chronic inflammation. Studies involving mast cell cultures revealed that molecules such as E-selectin, P-selectin, VCAM-1, and PECAM-1 are involved in adhesion to endothelium and rolling. These processes can lead to mast cell accumulation at the site of chronic inflammation and modulate the number of these cells in peripheral tissues [20]. Furthermore, PECAM-1 adhesion molecule is an important factor involved in the regulation of transendothelial migration of neutrophils. O'Brien et al. observed that interleukin $1 \beta$ (IL-1 $\beta$ ) induces PECAM-1-dependent transmigration that requires homophilic (PECAM-1-PECAM-1) engagement. While the cellular transmigration involving $\mathrm{IL}-8$ and leukotriene B4 is PECAM-1-independent, the process involving PECAM- 1 and IL-8 is a separate entity and additional cytokine components participate in the induction of transmigration [21].

\section{Conclusions}

Adhesion molecules play an important role in the development of inflammation. This study did not find significant differences in concentrations of such molecules as SEselectin and SPECAM-1 between patients with food allergy and gastritis and subjects in whom gastritis was not accompanied by atopic disorders. A positive correlation between concentrations of SPECAM-1 and E-selectin was observed in food allergy patients. Consequently, it can be concluded that these molecules participate in the pathogenesis of the inflammatory process independently of the etiopathogenesis of gastritis.

\section{References}

1. Crowe SE. Alergie pokarmowe. In: Gastroenterologia i choroby wątroby - posteppy w terapii [Polish]. Bayless TM, Diehl AM (eds.). Czelej, Lublin 2006; 375-82. 
2. Kaczmarski M, Wasilewska J, Jarocka-Cyrta E, et al. Polish statement on food allergy in children and adolescents. Postep Derm Alergol 2011; 28: 331-67.

3. Żukiewicz-Sobczak W, Krasowska E, Zwoliński J, et al. Allergic diseases - current state of knowledge. Postep Derm Alergol 2012; 29: 451-5.

4. Kaczmarski M. Food allergy from diagnosis to treatment [Polish]. Alergia Astma Immunol 2006; 11 (Suppl. 1): 133-5.

5. Miki I, Kusano A, Ohta S, et al. Histamine enhanced the TNFalpha- induced expression of E-selectin and ICAM-1 on vascular endothelial cells. Cell Immunol 1996; 171: 285-8.

6. Tsouknos A, Nash GB, Rainger GE. Monocytes initiate a cycle of leucocyte recruiment when cocultured with endothelial cells. Atherosclerosis 2003; 170: 49-58.

7. Białek K, Białek S, Pachecka J. Adhesion molecules above the upper respiratory tract diseases [Polish]. Alergia 2000; 2: 39-41.

8. Bęc L, Karolczak MA. The role of systemic inflammatory response in cardiopulmonary bypass. Part two: leukocytes [Polish]. Nowa Pediatria 2001; 23: 20-6.

9. Holgate ST, Church MK, Lichtenstein LM. Allergy [Polish]. Czelej, Lublin 2003.

10. Zajkowska J, Grygorczuk S, Kondrusik M, et al. Adhesion molecules above the upper respiratory tract diseases [Polish]. Pol Merk Lek 2006; 21: 459-64.

11. Gołąb J, Jakóbisiak M, Lasek W, Stokłosa T. Immunology [Polish]. Wydawnictwo Naukowe PWN, Warsaw 2009.

12. Sampson HA. Food allergy - accutately identifying clinical reactivity. Allergy 2005; 60 (Suppl. 79): 19-24.

13. Seibold F. Food-induced immune response as origin of bowel disease. Digestion 2005; 71: 251-60.

14. Eigenmann PA. T lymphocytes in food allergy: overview of an intricate network of circulating and organ-resident cells. Pediatr Allergy Immunol 2001; 13: 162-71.

15. Bartuzi Z. Food allergy [Polish]. Oficyna Wydawnicza Mediton, Łódź 2006.

16. Laan MP, Baert MRM, Bijl AMH, et al Markers for early sensitization and inflammation in relation to clinical manifestations of atopic disease up to 2 years of age in 133 high-risk children. Clin Exp Allergy 2000; 3: 944-53.

17. Greenberger PA. Interactions between rhinitis and asthma. Symposium cont. Allergy Asthma Proc 2004; 25: 89-93.

18. Cao G, Fehrenbach ML, Wiliams JT, et al. Angiogenesis in platelet endothelial cell adhesion molecule-1- null mice. Am J Pathol 2009; 175: 903-15.

19. Cao G, O'Brien CD, Zhou Z, et al. Involvement of human PECAM- 1 in angiogenesis and in vitro endothelial cell migration. Cell Physiol 2002; 282: 1181-90.

20. Dudeck A, Leist M, Rubant S, et al. Immature mast cells exhibit rolling and adhesion to endothelial cells and subsequent diapedesis triggered by $\mathrm{E}$ - and P-selectin, VCAM-1 and PECAM-1. Exp Dermatol 2010; 19: 424-34.

21. O'Brien CD, Lim P, Sun J, Albelda SM. PECAM-1-dependent neutrophil transmigrations is independent of monolayer PECAM-1. Blood 2003; 101: 2816-25. 